\title{
3-O-Formyl -27-Hydroxyfusidic Acid: A New Metabolite of Fusidic Acid by Cunninghamella echinulata
}

\author{
Amany Elsayed Ragab $\oplus^{* 1}$, Abdel-Rahim Sayed Ibrahim $\oplus^{1}$ \\ and Francisco Léon $\oplus^{2}$
}

\author{
${ }^{1}$ Department of Pharmacognosy, Faculty of Pharmacy, Tanta University, Tanta (31527), Egypt \\ ${ }^{2}$ Department of Medicinal Chemistry, College of Pharmacy, University of Florida, FL 32610, USA
}

(Received December 18, 2019; Revised January 27, 2020; Accepted January 28, 2020)

\begin{abstract}
Minor metabolites of fusidic acid (1) using the fungus Cunninghamella echinulata NRRL 1382 were investigated for discovering previously unstudied reactions. An unprecedented fusidic acid derivative, 3- $O$ formyl-27-hydroxyfusidic acid (2) was isolated, and its chemical structure was fully elucidated using various spectroscopic techniques including 1D, 2D NMR and HRESIMS. This is the first report for formylation reaction by C. echinulata.
\end{abstract}

Keywords: Fusidic acid; Cunninghamella echinulata; 3-O-formylation. @ 2020 ACG Publications. All rights reserved.

\section{Fungal Source}

In the course of biotransformation studies of fusidic acid by Cunninghamella echinulata, we report the structure elucidation and biological evaluation of the new 3-O-formyl-27-hydroxyfusidic acid (2) (Figure 1). C. echinulata NRRL 1382 (ATCC 42616) was obtained from the American Type Culture Collection (ATCC).

\section{Previous Studies}

A variety of reactions such as oxidation, methylation, demethylation, hydroxylation and conjugation can be mediated by $C$. echinulata [1,2]. However, acylation by $O$ - formylation is not a common microbial transformation by $C$. echinulata. Synthesis using formylation for alcohol protection was considered uncommon due to the precautions and special reagents required [3-5]. The availability of microbial formylation would help in this regard.

In mammals, fusidic acid (1) is metabolised via C-27 or C-3 oxidation and glucuronide conjugation [6,7]. However, microbes mediate C-6 and C-7 hydroxylation, C-3 and C-6 oxidation and deacetylation of C-16 followed by spontaneous lactone formation [8-12]. In our recent studies, the side

* Corresponding author: E- Mail: amany.ragab@pharm.tanta.edu.eg (A. E. Ragab) 
chain of fusidic acid was oxidised at C-26 and C-27 by C. echinulata [13]. In the present study, we focused on investigating the minor metabolites of fusidic acid generated by this organism.

\section{Present Study}

Biotransformation process, following the published procedures [13], and the isolation of metabolite $\mathbf{2}$ are discussed in the supporting information.

3-O-Formyl-27-hydroxyfusidic acid (2): White powder; UV (MeOH) $\lambda_{\max } 220 \mathrm{~nm}$; IR $v_{\max }$ (KBr disc) $\mathrm{cm}^{-1}: 3460,2945,2936,1720,1445,1395,1256,1995$; HRESIMS positive mode $(\mathrm{m} / \mathrm{z}): 583.3237$ $[\mathrm{M}+\mathrm{Na}]^{+}$(calc. for $\left.\left[\mathrm{C}_{32} \mathrm{H}_{48} \mathrm{O}_{8}+\mathrm{Na}\right]^{+}, 583.3247\right)$, Low resolution ESIMS negative mode $(\mathrm{m} / \mathrm{z}): 559.3$ $[\mathrm{M}-\mathrm{H}]^{-} ;{ }^{1} \mathrm{H}$ NMR and ${ }^{13} \mathrm{C}$ NMR $\left(\mathrm{CDCl}_{3}\right)$ : see Table 1 .

Antimicrobial activity: Minimum inhibitory concentration of compound $\mathbf{2}$ was determined using the National Committee of Clinical Laboratory Standard and ATCC strains (Table S1, supporting information).

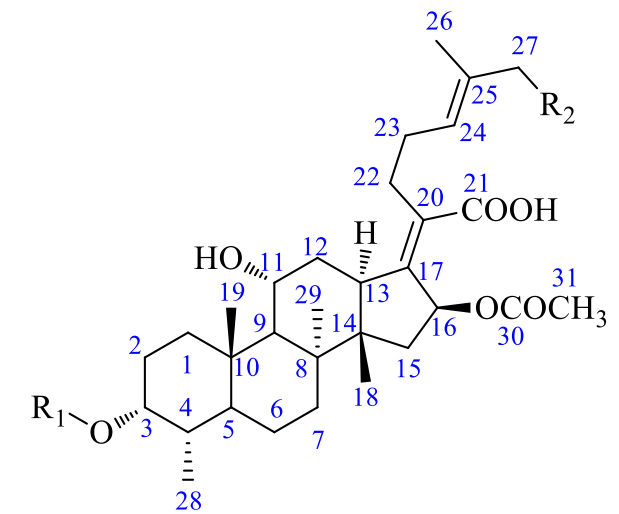

1: $\mathrm{R}_{1}=\mathrm{R}_{2}=\mathrm{H}$

2: $\mathrm{R}_{1}=\mathrm{COH}, \mathrm{R}_{2}=\mathrm{OH}$

Figure 1. Structures of fusidic acid and the isolated metabolite

HRESIMS of 2 in the positive ion mode showed an adduct ion at $\mathrm{m} / \mathrm{z} 583.3237$, which in conjunction with the ${ }^{13} \mathrm{C}$ NMR data, accounts for a molecular formula of $\left[\mathrm{C}_{32} \mathrm{H}_{48} \mathrm{O}_{8}+\mathrm{Na}\right]^{+}$(calculated 583.3247). In the negative ion mode, an adduct ion at $\mathrm{m} / \mathrm{z} 559.3$ for $[\mathrm{M}-\mathrm{H}]^{-}$was detected as the base peak. By detailed comparison of the molecular formula to the fusidic acid (1) $\left(\mathrm{C}_{31} \mathrm{H}_{48} \mathrm{O}_{6}\right)$, as well as, the ${ }^{1} \mathrm{H}$ and ${ }^{13} \mathrm{C}$ NMR data (Table 1 ) with compound $\mathbf{2}$, we conclude that compound $\mathbf{2}$ is an oxygenated fusidic acid analogue. The DEPT 135 spectrum of 2 exhibited nine methylene carbons compared to the eight of fusidic acid (1). ${ }^{1} \mathrm{H}$ NMR spectrum (Table 1) of $\mathbf{2}$ showed the presence of a singlet at $\delta_{\mathrm{H}} 3.93$ ppm integrated for two protons with the absence of the methyl singlet for one of the gem-dimethyl in the fusidic acid nucleus. The low shifted signal in the ${ }^{13} \mathrm{C}$ NMR (Table 1) spectrum at $\delta_{\mathrm{C}} 67.4$ suggested the hydroxylation at C-27/C-26. Homonuclear 2D NMR experiments COSY and NOESY of compound 2 (supporting information) showed the correlation of the proton at C-24 and the signal at $\delta_{\mathrm{H}}$ 3.93 confirming the hydroxylation site at C-27 due to its $E$ configuration [13]. ${ }^{13} \mathrm{C}$ NMR data for compound 2 indicated the carboxylic carbon at $\delta_{\mathrm{C}} 174.4$ for C-21 and the carbon of the ester group appeared at $\delta_{\mathrm{C}} 171.2$ which were found to correlate to the signals for $\mathrm{H}-22$ at $\delta_{\mathrm{H}} 2.60$ and the methyl ester at $\delta_{\mathrm{H}} 1.99$, respectively as shown by HMBC spectrum. ${ }^{1} \mathrm{H}$ NMR spectrum displayed down shifted $\mathrm{H}-3$ at $\delta_{\mathrm{H}} 5.09$ which is correlated to $\delta_{\mathrm{C}} 74.2$ in its HMQC experiment (supporting information), this shift suggested electronegative substitution at C-3. ${ }^{1} \mathrm{H}$ NMR and ${ }^{13} \mathrm{C}$ NMR data indicated a signal for 
carbonyl group at $\delta_{\mathrm{C}} 161.1$ attached to one proton signal at $\delta_{\mathrm{H}} 8.14$ which was found weakly correlated to $\mathrm{H}-3$ as shown in COSY spectrum, and to C-3 as indicated by HMBC. These data indicate the presence of a formyl group at C-3 attached through the oxygen atom. Other proton and carbon shifts of compound 2 were similar to those of fusidic acid. The stereochemistry of formyl group at C-3 was assigned as $(\alpha)$ due to the absence of large coupling of H-3 with H-2 and/or H-4 [14]. These data confirmed the structure of compound $\mathbf{2}$ as 3-O-formyl-27-hydroxyfusidic acid (Figure 1).

The reactions involved for converting fusidic acid to compound $\mathbf{2}$ are considered unique. Compound 2 was not detected in the control experiments which negates its being a microbial metabolite or an artefact. The control experiments were one in which fusidic acid was added to the media without fungus and the second control was fungus without the addition of fusidic acid. Both control experiments were treated as the test experiment. No previous data showed microbial $O$ formylation of steroids. The only natural $O$-formyl derivative of steroids discussed in literature was a postulated intermediate for the removal of 14- $\alpha$-methyl in sterol biosynthesis [15]. However, synthetic 3-O-formyl derivatives of fusidic acid were used as intermediates for the preparation of 24,25-dihydro and 17,20-dihydrofusidic acid derivatives in which a mixture of acetic anhydride, formic acid and formic anhydride was used at $5^{\circ} \mathrm{C}$ to $50^{\circ} \mathrm{C}$ in dichloromethane and dimethylaminopyridine as solvents and stirred for $20 \mathrm{~h}$ at room temperature [16-18]. Chemical formylation of alcohols requires drastic conditions and expensive catalysts [3-5]. The use of formic acid alone as a formylating agent is only applicable under very acidic conditions which can be achieved via the use of catalysts such as $\mathrm{Al}\left(\mathrm{HSO}_{4}\right)_{3}$ [3-5], ruling out that the use of formic acid in our procedure (under the conditions described in the experimental section 1.4) can be the formylation source. This observation was confirmed by failure of formylating 27-hydroxyfusidic acid using $0.2 \%$ formic acid in $30 \%$ ethyl acetate in toluene with or without silica addition and at room temperature or higher $\left(50-60^{\circ} \mathrm{C}\right)$. The enzyme(s) catalyzing 3-O-formylation should be of interest for further harnessing in the preparation of biomolecules to overcome the difficulties faced in chemical synthesis. By searching the genome of $C$. echinulata (https://genome.jgi.doe.gov/cgi-bin/metapathways?db=Cunech1), no enzyme was annotated as formyl transferase, however, two proteins (EC 1.14.99 and 1.14.11) were assigned as uncharacterized of which EC 1.14.11 is annotated as $\alpha$-ketoglutarate dioxygenase. 3-O-Formylation may be achieved via $O$-methylation followed by oxidation. Extensive studies towards exploring the mechanism of this kind of reaction are deemed to be necessary.

Fusidic acid is clinically used since 1960 s and it is active against methicillin resistant Staphyllococcus aureus [19,20]. Investigation of the impact of the structural changes of 2 from fusidic acid (1) on the antimicrobial activity revealed that the hydroxylation at $\mathrm{C}-27$ and 3-O-formylation greatly diminished the antimicrobial activity (Table S1, supporting information). The tested strains were S. aureus ATCC 25923 (methicillin resistant Gram-positive strain), Escherichia coli ATCC 25922 (anaerobic Gram- negative strain), Pseudomonas aeruginosa ATCC 15442 (aerobic Gramnegative strain) and Candida albicans ATCC 10231 (for testing antifungal activity). Compound 2 exhibited an MIC of $1000 \mu \mathrm{g} / \mathrm{mL}$ against $S$. aureus, about 2000 -fold of fusidic acid and 400 -fold of 27-hydroxyfusidic acid [13]. Thus, compound 2 retained only $0.038 \%$ of fusidic acid activity. Also, compound 2 has an MIC of $2000 \mu \mathrm{g} / \mathrm{mL}$ against C. albicans and E. coli, about 160 and 2000-fold of fusidic acid, respectively. Compound $\mathbf{2}$, as well as fusidic acid, has no activity against $P$. aeruginosa. The results confirm the importance of free hydroxyl group at C-3 for the activity against the tested strains and can be explained by weak or no binding of compound $\mathbf{2}$ to its target (elongation factor EF$\mathrm{G}$, involved in the protein synthesis) [12, 13]. Recently, blocking C-3-OH and C-21-COOH of fusidic acid generated derivatives that maintained the antibiotic activity with prolonged half-life [21].

In conclusion $C$. echinulata mediated $O$-formylation reaction specifically at $\mathrm{C}-3$ of fusidic acid. This is the first report of this reaction catalysis by C. echinulata. The isolated metabolite $\mathbf{2}$ exhibited only $0.038 \%$ of fusidic acid activity against methicillin resistant $S$. aureus which implies the requirement of free hydroxyl group at C-3 for maximum binding to the target. These results warrant further studies for testing the possibility of catalyzing formylation reactions for various substrates by C. echinulata. 
Table 1. ${ }^{1} \mathrm{H}$ NMR and ${ }^{13} \mathrm{C}$ NMR data of fusidic acid and the isolated compound $2,(\mathrm{~J}$ in $\mathrm{Hz})$

\begin{tabular}{|c|c|c|c|c|}
\hline Position & ${ }^{1} \mathrm{H}$ NMR & ${ }^{13} \mathrm{C}$ NMR & $\begin{array}{l}{ }^{1} \mathrm{H} \text { NMR } \\
(500 \mathrm{MHz})\end{array}$ & $\begin{array}{l}{ }^{13} \mathrm{C} \text { NMR } \\
(125 \mathrm{MHz})\end{array}$ \\
\hline 1 & $1.51(\mathrm{~m}) / 2.17(\mathrm{~m})$ & 30.2 & $1.55(\mathrm{~m}) / 2.10(\mathrm{~m})$ & 30.9 \\
\hline 2 & $1.75(\mathrm{~m}) / 1.86(\mathrm{~m})$ & 29.8 & $1.75(\mathrm{~m}) / 1.63(\mathrm{~m})$ & 27.4 \\
\hline 3 & $3.76(\mathrm{~s})$ & 71.5 & $5.09(\mathrm{~s})$ & 74.2 \\
\hline 4 & $1.58(\mathrm{~m})$ & 36.4 & 1.57 (brs) & 34.7 \\
\hline 5 & $2.11(\mathrm{~m})$ & 36.0 & $2.09(\mathrm{~m})$ & 37.6 \\
\hline 6 & $1.13(\mathrm{~m}) / 1.59(\mathrm{~m})$ & 20.9 & $1.15(\mathrm{~m}) / 1.61(\mathrm{~m})$ & 20.6 \\
\hline 7 & $1.12(\mathrm{~m}) / 1.74(\mathrm{~m})$ & 32.1 & $1.11(\mathrm{~m}) / 1.75(\mathrm{~m})$ & 32.5 \\
\hline 8 & & 39.5 & & 39.3 \\
\hline 9 & $1.57(\mathrm{~s})$ & 49.3 & 1.57 (brs) & 48.7 \\
\hline 10 & & 36.9 & & 36.8 \\
\hline 11 & 4.35 (brs) & 68.2 & 4.31 (brs) & 68.6 \\
\hline 12 & $1.85(\mathrm{~m}) / 2.33(\mathrm{~m})$ & 35.6 & $1.85(\mathrm{~m}) / 2.46(\mathrm{~m})$ & 35.1 \\
\hline 13 & $3.06(\mathrm{~d}, 10.91)$ & 44.3 & $2.97(\mathrm{~d}, 11.20)$ & 44.4 \\
\hline 14 & & 48.7 & & 49.3 \\
\hline 15 & $1.30(\mathrm{~d}, 14.20) / 2.19(\mathrm{~m})$ & 38.9 & $1.30(\mathrm{~m}) / 2.19(\mathrm{~m})$ & 38.9 \\
\hline 16 & $5.88(\mathrm{~d}, 8.32)$ & 74.5 & $5.83(\mathrm{~d}, 8.00)$ & 74.2 \\
\hline 17 & & 150.7 & - & 149.9 \\
\hline 18 & $0.89(\mathrm{~s})$ & 17.8 & $0.92(\mathrm{~s})$ & 17.9 \\
\hline 19 & $0.96(\mathrm{~s})$ & 23.0 & $1.00(\mathrm{~s})$ & 22.7 \\
\hline 20 & (1) (3) & 129.6 & (10) & 129.9 \\
\hline 21 & - & 174.4 & - & 174.4 \\
\hline 22 & $2.46(\mathrm{~m})$ & 28.8 & $2.60(\mathrm{~m})$ & 27.2 \\
\hline 23 & $2.07(\mathrm{~m}) / 2.17(\mathrm{~m})$ & 28.5 & $2.07(\mathrm{~m}) / 2.10(\mathrm{~m})$ & 26.8 \\
\hline 24 & $5.10(\mathrm{t}, 6.97)$ & 123.1 & $5.45(\mathrm{t}, 7.09)$ & 123.5 \\
\hline 25 & & 132.6 & & 135.5 \\
\hline 26 & $1.60(\mathrm{~s})$ & 17.8 & $1.65(\mathrm{~s})$ & 13.7 \\
\hline 27 & $1.67(\mathrm{~s})$ & 25.7 & $3.93(\mathrm{~s})$ & 67.4 \\
\hline 28 & $0.90(\mathrm{~d}, 5.8)$ & 15.9 & $0.86(\mathrm{~d}, 6.68)$ & 15.6 \\
\hline 29 & $1.38(\mathrm{~s})$ & 23.9 & $1.38(\mathrm{~s})$ & 24.3 \\
\hline 30 & - & 170.7 & - & 171.2 \\
\hline 31 & $1.96(\mathrm{~s})$ & 20.6 & $1.99(\mathrm{~s})$ & 20.7 \\
\hline Formyl & - & - & 8.14 & 161.1 \\
\hline
\end{tabular}

$*$ Data of fusidic acid (1) taken from reference [22].

\section{Acknowledgments}

We thank Dr. Lamiaa Al-madboly for carrying out the antimicrobial analysis of the isolated metabolite at the Faculty of Pharmacy, Tanta University, Egypt.

\section{Supporting Information}

Supporting Information accompanies this paper on http://www.acgpubs.org/journal/recordsof-natural-products

\section{ORCID}

Amany Elsayed Ragab: 0000-0001-8276-5397

Abdel-Rahim Sayed Ibrahim: 0000-0002-6854-4798

Francisco Léon: 0000-0002-5064-2381 


\section{References}

[1] S. Asha and M. Vidyavathi (2009). Cunninghamella- A microbial model for drug metabolism studies, Biotechnol. Adv. 27, 16-29.

[2] P. J. Davis (1988). Microbial models of mammalian drug metabolism, Dev. Indust. Microbiol. 29, $197-$ 219.

[3] K. Morita, S. Noguchi and M. Nishikawa (1959). Studies in steroids. XIII. Formylation of steroid alcohols with dimethylformamide-phosgene complex, Chem. Pharm. Bull. 7(8), 896-897.

[4] F. Shirini, M. A. Zolfigol, M. Abedini and P. Salehi (2003). Al $\left(\mathrm{HSO}_{4}\right)_{3}$ Catalyzed acetylation and formylation of alcohol, Bull. Korean Chem. Soc. 24(11), 1683-1685.

[5] V. Srivastava, A. S. Negi, J. K. Kumar and M. M. Gupta (2006). A simple convenient and chemoseclective formylation of sterols by Vilsmeier reagent, Steroids 71, 632-638.

[6] D. S. Reeves (1987). The pharmacokinetics of fusidic acid, J. Antimicrob Chemother. 20, 467-476.

[7] W. O. Godtfredsen and S. Vangedal (1966). On the metabolism of fusidic acid in man, Acta Chem. Scand. 20,1599-1607.

[8] K. Hadara, K. Tomita, K. Fujii, N. Sato, H. Uchida, K. Yazawa and Y. Mikami (1999). Inactivation of fusidic acid by pathogenic Nocardia, J. Antibiot. (Tokyo) 52(3), 335-339.

[9] W. Von Daehne, H. Lorch and W. O. Godtfredsen (1968). Microbial transformation of fusidane-type antibiotics, A correlation between fusidic acid and and helvolic acid, Tetrahedron lett. 47, 4843-4846.

[10] W. Dvnoch, G. Greenspan and H. E. Alburn (1966). Microbiological oxidation of fusidic acid, Experientia VIII, 517-517.

[11] B. Von der Harr and Schrefmp (1995). Purification and characterization of a novel extracellular Streptomyces lividans 66 enzyme inactivating fusidic acid, J. Bacteriol. 177, 152-155.

[12] A. S. Ibrahim and A. E. Ragab (2018). Fusidic acid ring B hydroxylation by Cunninghamella elegans, Phytochemistry Lett. 25, 86-89.

[13] A. S. Ibrahim, K. Elokely, D. Ferreira and A. E. Ragab (2018). Microbial oxidation of the fusidic acid side chain by Cunninghamella echinulata, Molecules 23, 970-980.

[14] L. Evans, J. N. Hedger, D. Brayford, M. Stavri, E. Smith, G. O’Donnell, A. I. Gray, G. W. Griffith and G. Simmon (2006). Antibacterial hydroxy fusidic acid analogue from Acremonium crotocinigenum, Phytochemistry 67, 2110-2114.

[15] R. T. Fischer, J. M. Trazakos, R. L. Magolda, S. S. Ko, C. S. Brosz and B. Larsen (1991). Lanosterol 14 alpha-methyl demethylase. Isolation and characterization of the third metabolically generated oxidative demethylation intermediate, J. Biol. Chem. 266(10), 6124-6132.

[16] T. Duvold and W. Von Daehne (2003). Fusidic acid derivatives, European Patent, Patent number $1232173 \mathrm{~B} 1$.

[17] W. Von Daehne, W. O. Godtfredsen and P. R. Rasmussen (1979). Structure-activity relationships in fusidic acid - type antibiotics, Adv. Appl. Microbiol. 25, 95-145.

[18] W. Von Daehne and P. R. Rasmussen (1979). Fusidic acid derivatives, United States Patent, Patent number 4162259.

[19] J. Turnridge, (1999). Fusidic acid pharmacology, pharmacokinetics, and pharmacodynamics, Int. J. Antimicrob. Agents 12, S23-S34.

[20] P. Collignon and J. Turnidge (1999). Fusidic acid in vitro activity, Int. J. Antimicrob. Agents 12, S45S58.

[21] J. Lu, J.X Ni, , J.A Wang, Z.Y Liu, K.L Shang and Y. Bi (2019). Integration of multiscale molecular modeling approaches with the design and discovery of fusidic acid derivatives, Future Med. Chem. 11(12), 1427-1442.

[22] N. Rastrup-Andersen and T. Duvold (2002). Reassignment of the ${ }^{1} \mathrm{H}$ NMR spectrum of fusidic acid and total assignment of ${ }^{1} \mathrm{H}$ and ${ }^{13} \mathrm{C}$ NMR spectra of some selected fusidane derivatives, Mag. Res. Chem. 40, 471-473.

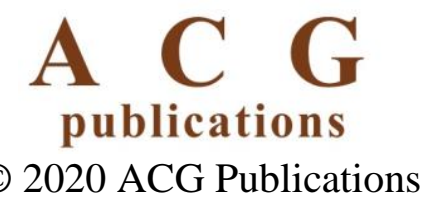

